\title{
The Computer Science Education Collaborative: Promoting Computer Science Teacher Education Programs for Preservice and In-service Teachers
}

\author{
Regina Toolin \\ University of Vermont \\ Burlington, VT \\ Regina.Toolin@uvm.edu
}

\author{
Lisa Dion \\ University of Vermont \\ Burlington, VT \\ Lisa.Dion@uvm.edu
}

\author{
Robert Erickson \\ University of Vermont \\ Burlington, VT \\ Robert.Erickson@uvm.edu
}

\begin{abstract}
This article reports on the efforts of the Computer Science Education Collaborative during the period between 2018-2020 to develop and implement a new computer science licensure program for preservice teachers seeking a license to teach computer science in grades 7-12 in Vermont. We present a brief review of the literature related to computer science teacher education and describe the process of developing the computer science education minor and major concentration at the University of Vermont. As a form of reflection, we discuss the program development process and lessons learned by the collaborative that might be informative to other institutes of higher education involved in CS teacher education program design and implementation. Finally, we describe next steps for developing in-service licensure programs for teachers seeking computer science professional development or licensure in grades 7-12.
\end{abstract}

\section{Keywords}

Computer Science Education, Computer Science Standards, Rural Education, Micro-credentials, In-service and Preservice Teachers

\section{INTRODUCTION}

Despite national efforts to highlight Computer Science (CS) education and careers in the U.S., a comparatively small percentage of students pursue CS postsecondary degrees and careers [1] Computing represents two-thirds of projected new STEM jobs in the U.S., but only $4 \%$ of college students overall earn a CS degree [13]. Computing and information technologies (IT) have driven many aspects of Vermont's economic growth, as evidenced by the presence of Dealer.Com, NRG Systems, Competitive Computing, IBM, Global Foundries, the Vermont Technology Alliance, and over 200 other related companies statewide. Vermont's IT future is bright; however, there is a gap between CS employment opportunities and CS learning opportunities available for $\mathrm{K}-12$ students and teachers in the state.

Opportunities to learn CS in Vermont demonstrate some signs of improvement over the past few years. In 2020, $60 \%$ of VT high schools reported offering CS courses as part of the curriculum [7].

Permission to make digital or hard copies of all or part of this work for personal or classroom use is granted without fee provided that copies are not made or distributed for profit or commercial advantage and that copies bear this notice and the full citation on the first page. To copy otherwise, or republish, to post on servers or to redistribute to lists, requires prior specific permission and/or a fee. Copyright @JOCSE, a supported publication of the Shodor Education Foundation Inc.

(C) 2021 Journal of Computational Science Education DOI: https://doi.org/10.22369/issn.2153-4136/12/1/1
However, when data are disaggregated for socioeconomic status, ethnicity, and gender, only $50 \%$ of rural high schools in VT offer CS courses.

Opportunities for underrepresented and underserved students to engage in CS learning have also been limited in that $28 \%$ are female, 7\% Latinx, 9\% Asian, and no African American or Native American students took AP CS exams during this period [7].

Over $62 \%$ of $\mathrm{K}-12$ principals in VT believe CS should be a required core class; however, limited funds for hiring and training teachers is cited as the primary barrier for offering CS courses at their schools (Code.org, 2019). In 2019, a state-wide survey of teachers $(n=270)$ conducted by the VT Agency of Education (AOE) found that $51 \%$ of respondents engaged students in some form of CS activities including Code.org Hour of Code, Lego robotics, makerspace, or other coding activities. Approximately 20\% reported having after-school computer clubs at their school, and $27 \%$ engaged in CS professional development. In 2017, approximately 200 new secondary teachers were prepared to teach CS in the US [12]; however, no teachers graduated from a Vermont institute of higher education (IHE) prepared to teach CS during this period $[12,6]$. To date, only 27 out of approximately 8,000 teachers are licensed to teach CS in VT.

In 2018, the Computer Science Education Collaborative (CSEC) was established by the University of Vermont's (UVM) College of Education and Social Services (CESS) and College of Engineering and Mathematical Sciences (CEMS) and the Vermont Agency of Education (VT AOE) with the primary mission to address the gaps and inequities in CS learning opportunities for students and teachers in Vermont. The CSEC prioritized the development of a new CS licensure program for preservice teachers seeking an initial CS licensure endorsement in grades 7-12. Following a comprehensive review process, the CS licensure program was approved by the UVM Faculty Senate and Board of Trustees in May 2019 followed by approval from the VT Agency of Education in May 2020.

This article reports on the efforts of the CSEC to develop and implement a new computer science licensure program for preservice teachers seeking a license to teach CS in grades 7-12. What follows is a brief review of pertinent literature related to computer science teacher education in the US, a description of the computer science education minor and major concentration at UVM, a reflection on the program development process, and lessons learned by the collaborative that might be informative to other IHEs involved in CS teacher education program design and implementation. Finally, we offer some insights into next steps for the development of in-service licensure programs for teachers seeking CS professional licensure in grades 7-12. 


\section{RESEARCH ON COMPUTER SCIENCE TEACHER EDUCATION}

A number of CS professional education programs and pathways are now available for teachers to acquire the knowledge, skills and practices leading to certification to teach $\mathrm{CS}$ in $\mathrm{K}-12$ environments across the US [4]. Currently, three distinct types of CS teacher certification pathways exist including subject, course-specific, and local education agency (LEA) determined pathways. States with subject certifications require the same teacher certification for any CS course taught. Course-specific states have different requirements depending on the specific CS course teachers plan to teach. LEA states have no state-wide certification requirements for teaching CS courses; an LEA sets these requirements for their district.

With limited pathways to CS certification in the US, Code.org recommends that LEAs allow teachers who currently teach CS or who have some CS professional learning experiences to teach CS under a temporary license. In this pathway, teachers may pursue an "add-on endorsement" that includes CS methods and content requirements to be earned, possibly through a certification assessment or 12 credit hours of coursework. Code.org also suggests the development of a full certification pathway that includes CS content courses, general education coursework, and computer science methods and practice teaching [4].

In Utah, a course-specific state, different levels of endorsement pathways provide less intimidating entry points for teachers without a CS background [4]. To earn a credential to teach Exploring Computer Science, teachers must complete Code.org CS Fundamentals, Teaching Methods (ECS PD), and an Industry test (Certiport IC3). A CS Level 1 endorsement allows teachers to teach AP Computer Science Principles and Computer Programming 1 and 2 upon completion of Teaching Methods (ECS, CSP), 3 CS courses (CS50, Oracle, Bottega), and/or an Industry test (MTA, Oracle). A CS Level 2 endorsement requires Teaching Methods (ECS, CSP), 5 CS courses (includes the 3 for the CS Level 1 endorsement), and an Industry test (MTA, Oracle).

Micro-credentials provide a competency-based pathway to certification that recognizes a teacher's existing expertise and increases accessibility by making certification job-based and less costly [5]. Micro-credentials are performance-based, allowing for teachers to demonstrate competency in content and pedagogy and can be "stacked" together in order to meet endorsement requirements. For example, Arizona allows teachers to be licensed through 12 credit hours of course work (for grade 6-12 CS endorsement) and requires fifteen hours of professional learning or an analogous micro-credential to be equivalent to one credit hour [5]. Micro-credentialing opportunities are provided through programs like BloomBoard CS Micro-credentials that facilitate the earning of micro-credentials: for example, "understanding cultural differences" and "using formative assessment to modify future instruction" [2].

Currently, Vermont is a subject certification state where preservice teachers must meet state computer science endorsement standards and the equivalent of a CS minor to teach CS in grades 7-12. In addition, preservice teachers must successfully complete a practicum and student teaching experience, required education coursework (e.g. foundations, diversity, curriculum, special education, educational technology, and CS methods courses) and the VT Licensure Portfolio (VLP) to earn licensure in grades 7-12 computer science education.

\section{COMPUTER SCIENCE EDUCATION PROGRAM DESCRIPTION}

The University of Vermont (UVM) has an enrollment of 10,612 undergraduates, 1,552 graduate students, and 466 medical students with 1,685 full-time and part-time faculty and offers students choices for programs from among more than 100 undergraduate majors, 52 masters, and 25 doctorate degrees. UVM is the only research university in the state, the state's only Carnegie-classified Research-Extensive institution, and a leader in research expenditures among public universities with enrollments less than 15,000. Specialized computer science facilities include a new STEM complex, Vermont Advanced Computing Core (VACC), and the Vermont Complex Systems Center. These unique distinctions make UVM an ideal academic setting to support computer science education on its campus.

The College of Engineering and Mathematical Sciences (CEMS) houses the Department of Computer Science and has an enrollment of 400 undergraduates among BS degrees in Computer Science, Computer Science \& Information Systems, and Data Science, as well as a BA degree in Computer Science offered through the College of Arts and Sciences (CAS). Over 60 graduate students are enrolled in the Computer Science and Complex Systems \& Data Science degrees. The College of Education and Social Services (CESS) has the only nationally recognized Council for the Accreditation of Educator Preparation (CAEP) teacher preparation programs in Vermont. Faculty and staff work with 825 undergraduate and 370 graduate students in more than 30 programs housed in the Education, Leadership, and Social Work departments. The Secondary Education Program has an enrollment of 150 students who are required to meet all VT AOE Endorsement Standards and Vermont Licensure Portfolio (VLP) requirements for certification in grades 7-12. The new CS minor and major concentration are fully approved licensure programs for preservice teachers interested in teaching computer science in grades 7-12 in the Secondary Education Program.

\subsection{UVM's Computer Science Education Minor and Major Concentration}

In September 2018, the Computer Science Education Collaborative (CSEC), comprised of 2 faculty and 1 staff from the Computer Science Department, 3 faculty from the Department of Education, and the VT AOE State Director of Technology, met to begin the development of a new minor and major concentration in computer science education. This initiative was inspired by previous conversations between education faculty and the VT State Director regarding the recent revision of the Vermont Agency of Education Computer Science Endorsement Standards [15] as well the need for CS learning opportunities for students and teachers across Vermont. In order to advance its goals and objectives, the CSEC submitted and secured an internal STEM Education grant to support CS curriculum development work, CS professional development and a CS Summit for teachers hosted at UVM in August 2019. Early on in the collaborative's efforts, the CSEC biweekly meetings focused on the alignment of the VT AOE computer science endorsement standards with existing undergraduate CS and Education coursework. This process revealed that all CS endorsement standards were met by existing coursework with the exception of a CS content specific methods 
Table 1. VT AOE CS Endorsement Standards Grades 7-12

\section{Computer Science Knowledge Standards Adapted from VT AOE CS Endorsement Standards (2019)}

Historical Context - The candidate recognizes the historical development and contributions of individuals or groups, particularly from underrepresented populations related to CS.

Algorithmic Thinking - The candidate can demonstrate algorithmic problem-solving knowledge and skills, design solutions (e.g., problem statement and exploration, examination of sample instances, design, implementing solutions, testing, evaluation, revising).

Computing Systems - The candidate understands computing systems including networks, operating systems, hardware, software and the role of compilers and interpreters in translating languages into machine instruction

Networks and The Internet - The candidate can demonstrate a knowledge of types of networks, internet protocols, the relationship between clients and servers, and cybersecurity.

Data Analysis - The candidate can analyze data by collecting, aggregating, cleaning, and modeling the data through simulations, visualizations, and statistical models.

Algorithms and Programming - The candidate is fluent in at least one high-level language used in current pedagogy and can compare high-level languages, particularly object-oriented program design. This includes designing, implementing, testing, and debugging. Includes an understanding of problem-solving strategies, algorithm analysis, programming concepts.

Impacts of Computing - The candidate understands digital, ethical and intellectual property issues. Candidate is considerate of equitable use of technology for all, knows good digital citizenship, can identify and avoid online threats.

CS Sub-Disciplines - The candidate knows concepts, vocabulary, and issues in two or more CS sub-disciplines (abstract data types, advanced CS algorithms, computer architecture, network/data communications, physical computing, digital forensics, machine learning).

Performance Standards: The candidate demonstrates pedagogical understanding with teaching CS content. Includes planning instruction with problem-solving, current technology, verbal and written communication skills, cooperative learning, and both visual and active activities.

Additional Requirements: A minor in CS, or the equivalent, in undergraduate or graduate coursework. course that was subsequently developed in collaboration by the CSEC faculty and further described in Section 3.2 of this article. Submission of the CS education minor and major concentration proposals to college and university-wide Curricular Affairs Committees (CAC) occurred in October 2018 followed by approval by both the UVM Faculty Senate and Board of Trustees in May 2019.

This important milestone paved way for the VT Agency of Education Results Oriented Program Approval (ROPA) [16] process that grants institutes of higher education in Vermont the authority to recommend students for teaching licensure in specific disciplines. This process entailed an additional year of data gathering, reporting, proposal submission, and final ROPA approval in May 2020.

The new CSE minor and major concentration reflect the essential knowledge and skills that computer literate students and teachers need to communicate and interact in today's world. All CSE courses are aligned to the VT AOE CS Endorsement Standards (See Table 1) and are offered through the Departments of Computer Science and Education.

Each of the required CSE content courses emphasizes a variety of attributes of computational and abstract thinking skills that also includes a required calculus class. Enrollment in the CSE preservice teacher program began in Fall 2020 with the initial expectation of modest interest from students primarily in the secondary education program seeking initial and/or dual licensure or computer science majors seeking a double major in CS and secondary education or a Master of Arts in Teaching as an accelerated master's student. The required CSE courses for the minor include 5 CS courses and $1 \mathrm{CS}$ methods course, and $9 \mathrm{CS}$ courses plus the equivalent of an education major for the CS major concentration (See Table 2).

Table 2. CSE Minor (19 Credits) and Major Concentration (31 Credits) Requirements

\begin{tabular}{|l|}
\hline CS 008: Introduction to Web Design -3 credits \\
\hline CS 021: Introductory Programming -3 credits \\
\hline CS 064: Discrete Structures -3 credits (major only) \\
\hline CS 087: Introduction to Data Science -3 credits \\
\hline CS 110: Intermediate Programming - 4 credits (Prerequisite: \\
CS 021) \\
\hline CS 121: Computer Organization - 3 credits (Prerequisite: CS \\
110) \\
\hline CS 124: Data Structures and Algorithms (Prerequisites: Math \\
021, CS 064, CS 110) - 3 credits (major only) \\
\hline CS 166: Cybersecurity Principles - 3 credits (major only) \\
\hline CS 292: Senior Seminar - 1 credit (major only) \\
\hline CS 091: Instructing in Computer Science (recommended) \\
\hline Math 021: Calculus 1 - 4 Credits \\
\hline EDSC 237: Teaching Computer Science in Secondary School \\
\hline - 3 credits \\
\hline
\end{tabular}


All content courses listed as requirements for the CSE minor and major concentration are currently offered through the CS and Mathematics departments. The methods course is offered through the Education department. Secondary education students enrolled in the CS major concentration will complete all 3 phases of the secondary education program including content requirements, university general education and diversity requirements and professional education requirements. See Table 3 for a summary of these requirements.

Table 3. Secondary Education Professional Education Requirements - 46 Credits

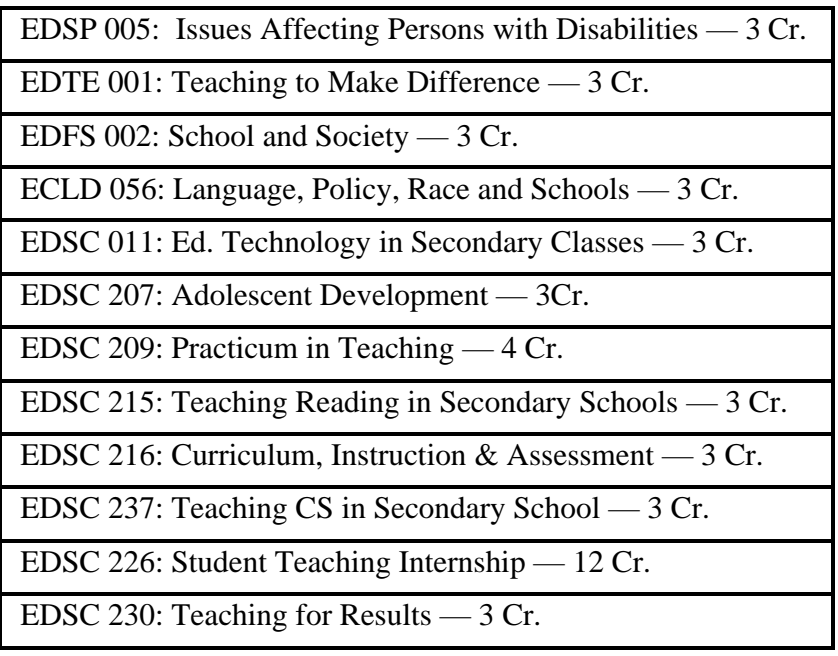

\subsection{Teaching Computer Science in Secondary School}

Teaching Computer Science in Secondary School (EDSC 237), a "methods" course developed in collaboration with CS and Education faculty, is required for students enrolled in both the CSE minor and major concentration. This course explores multiple theories and practices of teaching, learning, and assessing computer science in middle school and high school and is aligned to both the Computer Science Teachers Association (CSTA) K-12 Standards [8] and the VT AOE Computer Science Education Endorsement Standards [15]. The course places an emphasis on modeling critical dialogue and reflection about such topics as the nature of computer science; the structure of computer science disciplines; computer science learning standards; best practices of teaching and assessing computer science; and social, legal, ethical, and cybersecurity issues in computer science and computer science education.

EDSC 237 is a capstone course that students take near the completion of CSE program requirements. EDSC 216 Curriculum, Instruction and Assessment is a prerequisite for EDSC 237 and provides students with the opportunity to develop and apply fundamental knowledge and skills of lesson, assessment, and unit development to their emergent teaching practice. EDSC 237 builds on these pedagogical skills and provides students with multiple opportunities to develop and pilot a variety of CS lessons in a "critical friends" environment with their peers.

EDSC 237 is participatory in nature and practice. Each week, the instructors and students model and present problem-based activities and place-based lessons and projects aligned to the CSTA learning standards and other essential practices necessary to become a master teacher of computer science. Problem-based learning is driven by challenging, open-ended problems with no one right answer. Students work as self-directed, active investigators and problem-solvers in small collaborative groups [10]. Project-based learning is a teaching method in which students gain knowledge and skills by working to investigate and respond to engaging and complex questions, problems, or challenges through scientific and computational thinking over an extended period of time [3]. Placebased education is the process of using the local community and environment as a starting point to teach hands-on, real-world learning experiences in computer science, language arts, mathematics, social studies, science, and other subjects across the curriculum. The goal of place-based learning in the context of teaching computer science is to help students integrate CS principles and practices into community-based projects while simultaneously enhancing students' appreciation for the natural world and creating a heightened commitment to serving as active, contributing citizens [11].

One of the primary outcomes of EDSC 237 is the development of a computer science resource portfolio or collection of related lessons, activities, projects, and assessments that preservice teachers can implement during student teaching. Students are required to align their lessons and activities to the CSTA learning standards and integrate the principles and practices of problembased, project-based, and place-based principles and practices into their CS resource portfolio. For more information about the methods course, please see the EDSC 237 syllabus [14].

\section{LESSONS LEARNED FROM THE COMPUTER SCIENCE EDUCATION COLLABORATIVE}

In order to assess the overall progress of the CSEC's work over the past two years, it was beneficial to utilize the evaluation framework of effective research-practitioner partnerships (RPP) developed by Henrick et al. [9]. In particular, our program assessment focused on the following questions: 1.) How did the CSEC work to develop trust and ensure that there was equitable participation among partners? 2.) How did the CSEC support the goals of the participating practitioners? 3.) How did the CSEC learn together? 4.) How will the CSEC ensure that the curriculum work that they have engaged in over the past two years will be fruitful?

\subsection{How did the CSEC develop trust and ensure there was equitable participation among partners?}

Initially, CSEC members consisted of 2 CS faculty, $1 \mathrm{CS}$ outreach coordinator, 3 education faculty, and the state director of technology. After CSE program approval in year 1, a CS teacher from a local school district joined the partnership. In order to keep the momentum moving forward, this diverse group of stakeholders made a commitment to attend and actively participate (in-person and virtually) in bi-weekly meetings for the purpose of accomplishing our CSE program development and implementation goals. We shared the workload by taking on various research, survey development, and standards alignment tasks. We established meeting norms that encouraged equal voice and input from all partners and invited participation from those who at times seemed reluctant to speak.

\subsection{How did the CSEC support the goals of the participating practitioners?}

Two of the CSEC partners were school practitioners who had fixed schedules with limited availability for meeting. As a collaborative, 
we agreed to conduct our meetings during times that were conducive to practitioners' schedules. As a result, we would often meet during lunch or after school hours. The collaborative made a genuine effort to better understand the roles and responsibilities of $\mathrm{K}-12$ classroom teachers as well as the overall Grade 7-12 school culture and environment. The CSEC was particularly interested in the experiences of one of our partners, a CS classroom teacher, who recently earned CS licensure endorsement through the VT AOE peer review process. Her testimonial informed the development of the CS methods course and was instrumental in conversations pertaining to next steps in developing CS licensure pathways for inservice teachers.

\subsection{How did the partnership learn together?}

As members of the CSEC, we recognized that each of us brought distinct knowledge and expertise that could advance both the project and the CSEC on the whole. CS faculty contributed in-depth knowledge of CS principles, processes, and practices aligned to VT CS endorsement standards and organized this data into a comprehensive spreadsheet that was invaluable to our program and course development work going forward. Education faculty and practitioners were instrumental in translating the curricular and pedagogical elements of the VT CS endorsement standards as well as in making recommendations for how topics such as equity, ethics, and cybersecurity might make their way into the CS methods course. In addition, on numerous occasions throughout the past two years, CSEC partners attended and presented at international, national, and regional CS conferences. In November 2019, four of the CSEC partners participated in a National Science Foundation CS for All workshop in DC to begin work on a CS for All grant proposal with the intent to develop and support CS pathways for VT in-service teachers.

\subsection{How will the CSEC ensure that the curriculum work that they engaged will be fruitful?}

After two years of collaborative work and the approval of the CSE minor and major at the university and state levels, we have met our targeted goals. Currently, the role of the CSEC has shifted from program development to program implementation, marketing, and recruitment. With the support of university administrators including chairs, deans, and communications directors, the CSEC is now focused on broadly advertising the CSE program via college websites, course catalogs, and program checklists for students. In addition, CS and Education faculty have been instrumental in directly communicating the progress and outcomes as well as new CSE program information to their departmental colleagues.

\section{NEXT STEPS: WHERE DO WE GO FROM HERE?}

Through the ongoing collective efforts of the CSEC, it became increasingly evident that the development of a preservice computer science education program was truly only the "tip of the iceberg" regarding the work that still needs to be accomplished in computer science education in Vermont. Given that only 27 teachers are currently licensed to teach CS in Vermont, word of the CSE program quickly spread to in-service teachers who were interested in earning licensure in computer science education. State-wide surveys conducted by the VT AOE and evaluations from a CS Summit hosted by the CSEC in 2019 confirmed our hunch that many teachers (over 300) were interested in CS professional learning opportunities and licensure. Teachers inquired as to whether the CSE minor or major concentration programs would be appropriate to their needs. In some cases, the answer was "yes," but in reality, the preservice CSE program was designed primarily for undergraduate or MAT graduate students who were interested in an initial CS licensure program.

This perceived need has prompted the CSEC to move forward in the development of flexible pathways for in-service teachers that recognize the limitations and constraints of teachers' professional and personal lives and offer alternative options for teachers to earn licensure in computer science. In addition to the traditional undergraduate program described in this article, the CSEC is currently working on 2 additional pathways: a CSE Certificate Pathway and a CSE Individually Designed Pathway for licensed teachers interested in computer science licensure. For the CSE Certificate pathway, in-service teachers would enroll in a blend of $\mathrm{CS}$ content and pedagogy courses aligned to the CS AOE endorsement standards that explore best curriculum and teaching practices. Courses would be offered primarily online with options for face-to-face workshops, seminars (synchronous and asynchronous), and field/practicum experiences offered during summer months. This pathway is designed for licensed teachers, as well as others seeking licensure endorsement and methods to integrate CS principles and practices into the 7-12 curriculum.

The CSE Individually Designed pathway is intended for teachers who may already have earned a number of required CSE credits and/or have participated in CS professional development workshops over time or who are new to CS principles and teaching. In this pathway, teachers would work with an advisor to curate a sequence of coursework, workshops (e.g. Code.org), as well as formal and informal CS teaching experiences that demonstrate evidence for meeting AOE CS endorsement standards leading to licensure. Teachers in this pathway would need to apply for the VT AOE peer review process and complete a portfolio that demonstrates how their courses and experiences meet $\mathrm{AOE}$ licensure endorsement standards. The development of these flexible pathways will be the primary focus of the work of the CSEC going forward.

The variety of CS professional learning opportunities described in this article have been designed to build preservice and in-service teachers' capacity to offer more authentic, engaging, and inquirybased CS education to their students. As Vermont and other states increasingly aim to provide high-quality CS education for all students, the Computer Science Education Collaborative through its efforts will continue to advance and support these initiatives over time.

\section{ACKNOWLEDGEMENTS}

The CSEC was funded by the University of Vermont STEM Education grant in order to support the development and implementation of the computer science minor and major concentration.

The authors would like to acknowledge Peter Drescher, Juniper Lovato, Heather Rogers, Katie Shepherd, and Alan Tinkler for their contributions to the CSEC over the past two years.

\section{REFERENCES}

[1] Robert D. Atkinson and Merrilea Mayo. 2010. Refueling the U.S. Innovation Economy: Fresh Approaches to Science, Technology, Engineering and Mathematics (STEM) Education. The Information Technology \& Innovation Foundation. Washington, D.C. Retrieved from https://itif.org/files/2010-refueling-innovation-economy.pdf. 
[2] BloomBoard, Inc. What Are Micro-credentials? Retrieved from https://bloomboard.com/what-are-microcredentials/.

[3] Buck Institute for Education. PBLWorks. Retrieved from https://www.pblworks.org/.

[4] Code.org. 2018. Everyone and No One Can Teach CS: Certifications Eligible to Teach CS (by State). Retrieved from

docs.google.com/document/d/1XA1zIjuR222BtRWTljNatC D6TYFAZan8eDWqZneG6I8.

[5] Code.org Advocacy Coalition. 2019. Micro-credentials: A Pathway for Certification and Professional Learning. Retrieved from https://advocacy.code.org/microcredentials.pdf.

[6] Code.org Advocacy Coalition and Computer Science Teachers Association (CSTA). 2018. 2018 State of Computer Science Education: Policy and Implementation. Retrieved from https://code.org/files/2018_state_of_cs.pdf.

[7] Code.org Advocacy Coalition, Computer Science Teachers Association (CSTA), and Expanding Computing Education Pathways (ECEP) Alliance. 2020. 2020 State of Computer Science Education: Illuminating Disparities. Retrieved from https://advocacy.code.org/2020_state_of_cs.pdf.

[8] Computer Science Teachers Association (CSTA) K-12 Standards. Retrieved from https://csteachers.org/page/aboutcsta-s-k-12-nbsp-standards.

[9] Erin C. Henrick, Paul Cobb, William R. Penuel, Kara Jackson, and Tiffany Clark. 2017. Assessing ResearchPractice Partnerships: Five Dimensions of Effectiveness. William T. Grant Foundation, New York, NY. Retrieved from https://wtgrantfoundation.org/library/uploads/2017/10/Assess ing-Research-Practice-Partnerships.pdf.
[10] Linda B. Nilson. 2010. Teaching at Its Best: A ResearchBased Resource for College Instructors (2nd ed.). JosseyBass, San Francisco, CA.

[11] David Sobel. 2004. Place-Based Education: Connecting Classrooms and Communities. Orion, Great Barrington, MA.

[12] United States Department of Education. 2019. Title II Higher Education Act: 2018 All States Report Data File. Retrieved from https://title2.ed.gov/Public/DataTools/2018/AllStates.xls.

[13] United States Department of Education, National Center for Education Statistics, Integrated Postsecondary Education Data System (IPEDS), Fall 2001 through Fall 2018, Completions component.

[14] The University of Vermont. Secondary Education Program: EDSC 237: Teaching Computer Science in Secondary Schools. Syllabus. Retrieved from https://drive.google.com/file/d/1AIaAA3ACUrKA3um_F1z4 kvr6wtAGbrkd/view

[15] The Vermont Standards Board for Professional Educators. Rules Governing the Licensing of Educators and the Preparation of Educational Professionals. Vermont Agency of Education Educator Quality Division. Retrieved from https://education.vermont.gov/sites/aoe/files/documents/Rule s\%20Governing $\% 20$ the $\% 20$ Licensing $\% 20$ of $\% 20$ Educators 9_20_2019.pdf

[16] The Vermont Standards Board for Professional Educators. Results Oriented Program Approval (ROPA) Handbook. Vermont Agency of Education Educator Quality Division. Retrieved from https://education.vermont.gov/sites/aoe/files/documents/edueducator-quality-ropa-handbook.pdf. 